\title{
Emergency vaccination alleviates highly pathogenic porcine reproductive and respiratory syndrome virus infection after contact exposure
}

\author{
Xiao Li ${ }^{1}$, Li Qiu ${ }^{2}$, Zengqi Yang ${ }^{2 *}$, Ruiyi Dang ${ }^{2}$ and Xinglong Wang ${ }^{2^{*}}$
}

\begin{abstract}
Background: To assess the effectiveness of emergency vaccination for reducing the contact-induced infection and pathological damage caused by the highly pathogenic porcine reproductive and respiratory syndrome virus (HPPRRSV), Twenty pigs were equally divided into four groups. Groups 1,2 and 3 were housed in one unit, whereas Group 4 was separately housed. Group 1 was challenged with HPPRRSV on day 0. Group 2 and 4 did not receive treatment and were used as the contact-infected and uninfected controls, respectively. Group 3 was treated with the attenuated vaccine at 0 days post-inoculation. The rectal temperatures, clinical signs, pathologic lesions and viraemia of the piglets were detected and evaluated.

Results: The vaccinated pigs in Group 3 showed less clinical morbidity, viraemia, temperature fluctuations and lung lesions at 14 days post-inoculation, as compared with the contact-infected (Group 2) and experimentally infected (Group 1) pigs. Higher serum IFN- $\gamma$ levels were detected among the pigs that received emergency immunisation. Thus, IFN- $\gamma$ may be involved in immunity against HPPRRSV infection.

Conclusions: These results indicated that emergency vaccination could effectively alleviate HPPRRSV infection during experimental contact exposure. Our findings provide a novel and useful strategy for controlling clinical HPPRRSV.
\end{abstract}

\section{Background}

The highly pathogenic porcine reproductive and respiratory syndrome virus (HPPRRSV) in China was first reported in 2006; the outbreak overwhelmed ten provinces (including autonomous cities or regions) with more than 2,000,000 infected pig within the first four months [1]. HPPRRSV was likewise reported in Vietnam, where it caused much economic loss to local farms [2]. Thus, HPPRRSV has emerged as one of the most important pathogens that threaten pig farms.

An HPPRRSV-derived attenuated vaccine was developed to control the disease [3]. The attenuated vaccine of a modified-live virus (MLV) derived from the American PRRSV VR-2332 has been widely used in PRRSV-prevalent countries, with its safety and effectiveness proven by previous studies [4,5]. However, clinical observations showed

\footnotetext{
* Correspondence: nwafucrb@gmail.com; wxlong@nwsuaf.edu.cn

${ }^{2}$ College of Veterinary Medicine, Northwest A\&F University, Yangling 712100, China

Full list of author information is available at the end of the article
}

that several MLV-vaccinated farms in China suffered from heavy economic losses caused by HPPRRSV in 2006 to 2010 [6]. This inconsistency revealed that the MLV vaccine provides limited protection from HPPRRSV under normal immunisation procedures.

Several farms in Jiangsu, China successfully reduced HPPRRSV damage using a promising emergency immunisation strategy with the MLV strain. An excess dose of the MLV vaccine (4 to 6 doses) was administered upon confirmation of HPPRRSV infection. Losses were reduced by $30 \%$ to $70 \%$, as compared with the untreated herds (unpublished data). Vaccine intervention against typical PRRSV has been previously studied. Although not as effective as a cure, vaccine intervention could reduce the persistence and transmission of PRRSV in a pig population infected with the heterogonous isolates [5,7].

This study aimed to replicate clinical cases under experimental conditions to confirm the effects of emergency immunisation, which may be widely used for emergency cases of HPPRRSV infection.

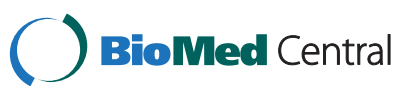

(c) 2013 Li et al.; licensee BioMed Central Ltd. This is an Open Access article distributed under the terms of the Creative Commons Attribution License (http://creativecommons.org/licenses/by/2.0), which permits unrestricted use, distribution, and reproduction in any medium, provided the original work is properly cited. 


\section{Methods \\ Virus}

The Northern American PRRSV isolate BB0907 was obtained from infected pigs in 2009, purified, and passaged using MARC-145 cells. The BB0907 isolate (9th passage on MARC-145) is highly virulent and caused high mortality in piglets in previous experimental infection experiments [8]. The widely used vaccine Ingelvac\&reg PRRS MLV was purchased from Ingelvac.

\section{Animals}

A total of 20 PRRSV-free crossbred (Landrace $\times$ local stock) pigs, approximately 28-days-old, were randomly distributed into four groups. Groups 1, 2 and 3 were housed in one unit, whereas Group 4 was housed in another.

All experimental procedures were approved by an independent animal care and use committee. The guidelines of the National Veterinary Research and Quarantine Service for the reproduction of pathogenesis in pigs were respected.

\section{Infection and immunisation}

The Group 1 pigs were intramuscularly injected with $2 \times 10^{4} \mathrm{TCID}_{50} / \mathrm{ml} \mathrm{BB0907}$ in $2 \mathrm{ml}$ Dulbecco's modified Eagle's medium at 0 day post-inoculation (DPI). The Group 3 pigs were intramuscularly vaccinated with three doses of Ingelvac $^{\circledR}$ PRRS MLV $\left(10^{5} \mathrm{TCID}_{50} / \mathrm{ml}\right)$ at 0 DPI. The pigs in the Groups 2 and 4 did not receive any treatment.

\section{Clinical and pathologic examination}

Rectal temperatures, clinical signs, pathologic lesions and viraemia were detected and evaluated following the procedures of our previous study [9]. Sera were collected at 0, 3, $5,7,10,14$ and 21 DPI to detect the virus load, serum IFN$\gamma$ concentration and PRRSV-specific antibody. At 3, 5, 7, 14 and $21 \mathrm{DPI}$, the following clinical signs were graded using a scale from 0 to 1: anorexia, lethargy, rough hair, dyspnoea and cough. Gross lung lesions (0 to 2 points) were evaluated based on gray mottling, oedema and consolidation. The severity of haemorrhage and the enlargement of lymph nodes were scored using three grades ( 0 to 2 points). All pigs were euthanised and necropsied on 21 DPI. Lung sections for histopathologic examination were collected and prepared, as previously described [10]. Lung histopathology was determined in terms of the degree of haemorrhage ( 0 to 1 point) and interstitial pneumonitis ( 0 to 1 point). The highest pathologic lesion score for the morbid pigs was 12 (total score of all the pathologic lesions).

\section{Antibody measurement}

Enzyme-linked immunosorbent assay (ELISA) S/P (Sample/Positive) ratios were determined using the HerdCheck ${ }^{\circledR}$ PRRS ELISA $2 \times \mathrm{R}$ (IDEXX Laboratories, Inc., Westbrook, ME, USA) according to the manufacturer's instructions. The sera were collected on $0,3,5,7,10,14$ and 21 DPI.

\section{Serum IFN- $\gamma$ concentration}

To detect IFN- $\gamma$ production in pigs, serum was collected at $0,3,5,7,14$ and 21 DPI for quantitative measurement of IFN- $\gamma$ using commercial ELISA kits (R\&D Systems, Minneapolis, MN, USA), according to the recommended protocol. The test had three replicates for each sample, and the data were presented as the mean \pm S.E.

\section{Viraemia detection}

Viraemia was determined at $0,3,5,7,14$ and 21 DPI by real-time polymerase chain reaction amplification using HPPRRSV-specific primers, as previously described [11]. To quantify the serum virus load, cDNA from cultured PRRSV (with a known TCID $_{50}$ ) was serially diluted by tenfold to generate a standard curve. The amount of virus in the samples was determined by linear extrapolation of the $C t$ value plotted against the standard curve.

\section{Statistical analysis}

All data are presented as mean \pm S.D. $\chi^{2}$-test was used to analyze the clinical signs and gross lesions of the animals after challenge. The cytokines and viremia data were evaluated using one-way repeated measurements ANOVA and least significance difference. Differences with $p<0.05$ were considered statistically significant.

\section{Results}

\section{Clinical signs and pathologic examination}

All pigs exposed to BB0907, except those in Group 3, exhibited high fever $\left(\geq 41^{\circ} \mathrm{C}\right)$ for more than five days (Figure 1). The pigs in Group 3 had slight temperature variations, with 2 pigs from this group experiencing a threeday fever of approximately $40.5^{\circ} \mathrm{C}$. Aside from the high fever, the appearance of typical HPPRRSV-induced characteristics was delayed for almost eight days in Group 3. As expected, the pigs in Group 4 had no relevant temperature changes throughout the duration of the experiment.

The clinical signs of HPPRRSV infection were observed at $3,5,7,10,14$ and $21 \mathrm{DPI}$; these included anorexia,

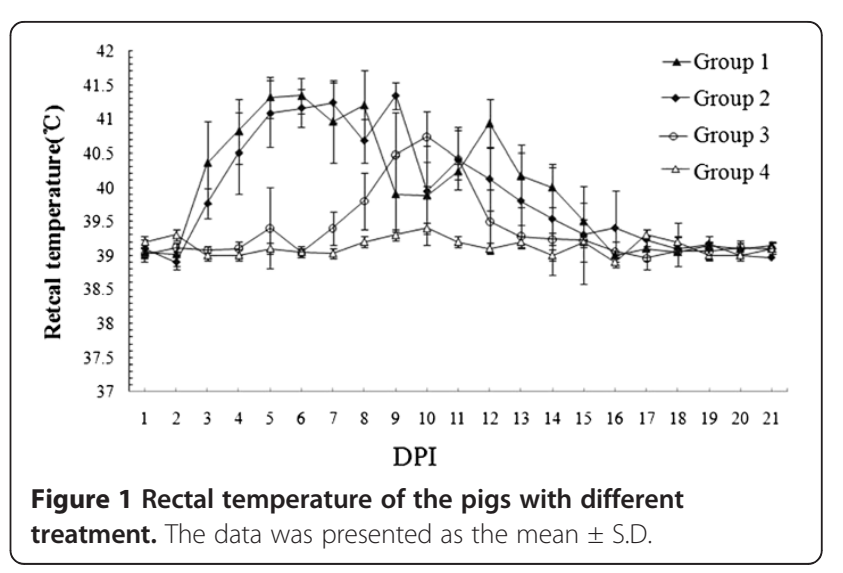


Table 1 Summary of infection and treatment results from piglets

\begin{tabular}{|c|c|c|c|c|c|c|c|c|c|c|c|c|c|}
\hline \multirow[b]{2}{*}{ Groups } & \multirow[b]{2}{*}{ Morbidity* } & \multirow[b]{2}{*}{ Mortality** } & \multicolumn{5}{|c|}{ Scores of clinical signs of each pig } & \multicolumn{6}{|c|}{ Scores of pathological lesions of each pig*** } \\
\hline & & & 3dpi & 5dpi & 7dpi & 14dpi & 21dpi & $1 \#$ & $2 \#$ & 3\# & 4\# & $5 \#$ & Mean \pm SD \\
\hline Group1 & $5 / 5$ & $3 / 5$ & 1.6 & 2.2 & 3.2 & 4.5 & 3.2 & 8 & 12 & 9 & 12 & 12 & $10.6 \pm 1.83^{\mathrm{a}}$ \\
\hline Group2 & $5 / 5$ & $2 / 5$ & 1 & 2 & 2.4 & 3 & 2.25 & 7 & 8 & 12 & 12 & 7 & $9.2 \pm 2 . .4^{\mathrm{a}}$ \\
\hline Group3 & $3 / 5$ & $0 / 5$ & 0 & 1.4 & 0.4 & 3.2 & 1.6 & 5 & 7 & 4 & 9 & 7 & $6.40 \pm 1.58^{b}$ \\
\hline Group4 & $0 / 5$ & $0 / 5$ & 0 & 0 & 0 & 0 & 0 & 1 & 2 & 0 & 0 & 0 & $1.00 \pm 0.89^{c}$ \\
\hline
\end{tabular}

* indicates numbers of ill pigs/total numbers of pigs within a group;

** indicates numbers of died pigs/total numbers of pigs within a group;

*** indicates mean scores of the clinical signs of living pigs;

\# labels the ear number of pigs within one group;

The different labeled letter "a,b, $c$ " in the last line indicates significant difference between different groups $(P<0.05)$.

lethargy, reddened skin, dyspnoea and cough. The pigs in Groups 1 and 2 exhibited anorexia, lethargy and reddened skin from 5 DPI to 7 DPI. Among the pigs in these groups, three had dyspnoea and cough at 7 DPI. At 10 DPI, 3 pigs in Group 1 and 2 pigs in Group 2 had died. By contrast, the pigs in Group 3 only demonstrated slight lethargy, and none of the individuals died during the experiment. The pigs in Group 4 likewise exhibited no clinical signs of infection. Significantly serious tissue lesions were observed in Groups 1 and 2, as compared with those in Groups 3 and 4. These results are summarised in Table 1.

The euthanised pigs were necropsied, during which their lungs and lymph nodes were examined. The results showed that the most serious gross lesions were observed in Groups 1 and 2, including gray mottling, oedema, lung consolidation, haemorrhage and lymph node enlargement. Only a few cases of minor gray mottling were observed in Group 3, with very slight signs of oedema and lung consolidation. The lungs of pigs in Group 4 were relatively clean, with one pig having a slight congestion. Microscopic lesions in the lungs were evaluated in terms of their septal thickening and haemorrhage. Lungs of the virus-inoculated pigs showed microscopic lesions characterised by some septal thickening and haemorrhage (Figure 2). Lungs collected from Groups 1 and 2 showed severe haemorrhage and septal thickening, whereas lungs from Group 3 only exhibited slight lesion. The lungs obtained from Group 4 were relatively healthy (Table 1).

\section{Antibody measurement}

The humoral immune response to PRRSV measured by the ELISA S/P ratios at 10 DPI showed that the average antibody titres of the virus-exposed groups exceeded the 0.4 cut-off for a positive result. By contrast, the control group averages were negative and remained below 0.4 until 21

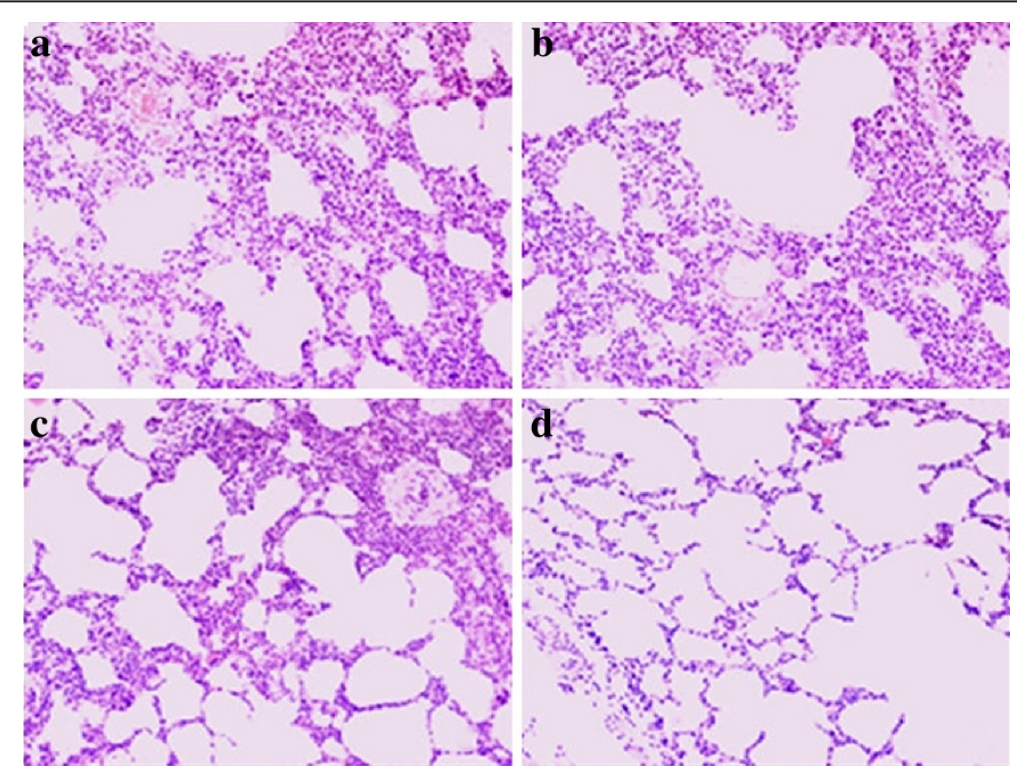

Figure 2 Microscopic examination of infected lungs compared with the healthy ones on 21 DPI. Hematoxylin- and eosin- stained sections of lungs in pigs from Group1 (a), Group 2 (b), Group 3 (d) and Group 4 (c) on 21 DPI. Images were obtained on an Olympus BX-50 light microscope at 200-fold original magnifications. 


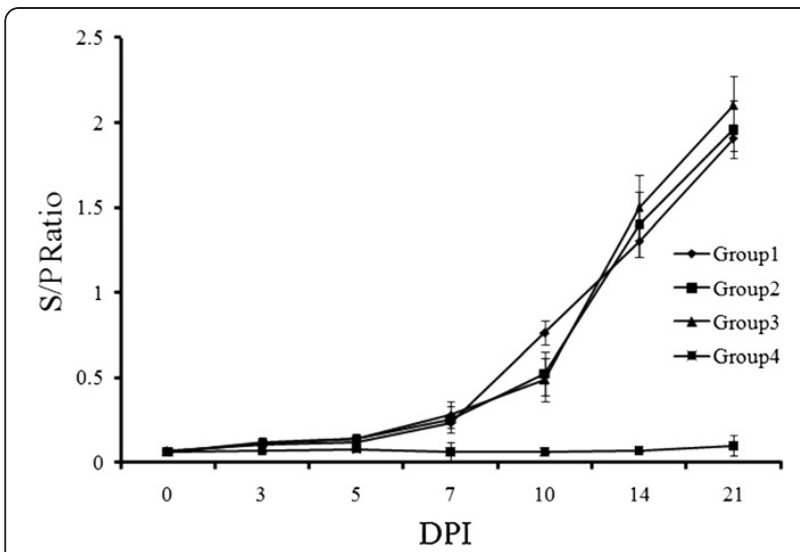

Figure 3 Kinetics of antibody response to PRRSV detected by commercial available ELISA kit. The serum samples $(n=5)$ were collected from 0 to $21 \mathrm{DPI}$ as indicated. Data were presented as the mean value of triplicate samples \pm S.D.

DPI. No significant differences were found among the first three groups (Figure 3).

\section{Viraemia}

The viraemia test demonstrated that the level of PRRSV transcripts in Groups 1 and 2 were significantly higher than that in Group 3 at both 7 and 10 DPI $(p<0.05)$ (Figure 4). A study to detect persisted infection in emergency immunised pigs should be conducted in future. PRRSV transcripts were not detected in Group 4 (Ct $\geq 40$, data not shown).

\section{IFN- $\gamma$ secretion}

High IFN- $\gamma$ serum levels were observed in the pigs exposed to the virus. The highest serum IFN- $\gamma$ concentration was observed in Group 3, which was administered the emergency vaccination. The higher IFN- $\gamma$ levels lasted

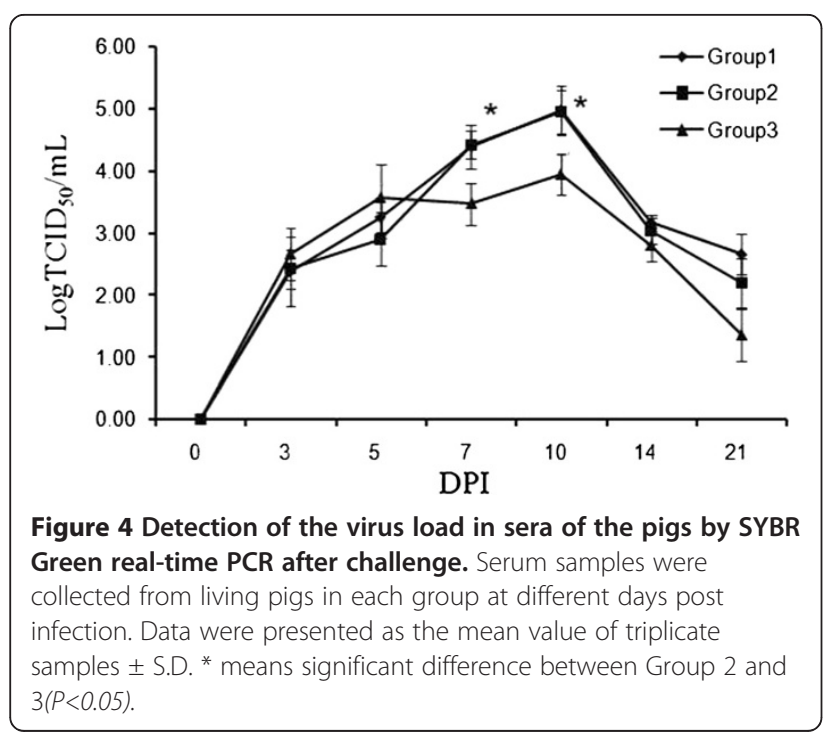

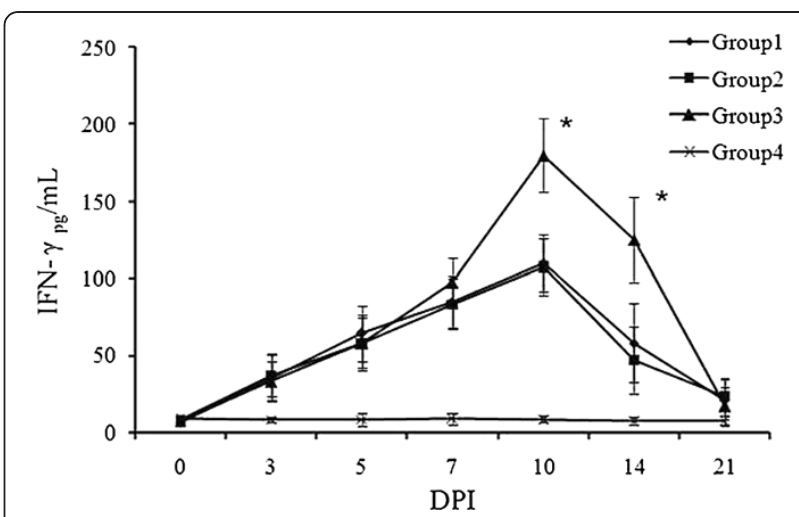

Figure $\mathbf{5}$ Sera IFN- $\boldsymbol{\gamma}$ levels detected by commercial ELISIA kit. The sera were collected from the pigs $(n=5)$ at $0,3,5,7,10,14$ and 21 DPI. Data were presented as the mean value of triplicate samples \pm S.D. * means significant difference between Group 2 and 3 $(P<0.05)$.

for approximately $14 \mathrm{DPI}$, and the peak was observed at 10 DPI (Figure 5).

\section{Discussion}

Emergency vaccination is a useful tool for controlling animal and human infectious diseases after exposure to pathogens, such as the foot-and-mouth disease virus (FMDV) [12], the classical swine fever virus (CSFV) [13], and rabies virus [14]. Emergency vaccination diminishes economic losses by reducing morbidity and mortality, as well as virus transmission. Post-exposure vaccination for typical PRRS has significantly reduced the number of persistently infected pigs at 127 DPI and reduced viral shedding to within 97 DPI [5]. In the present study, emergency vaccination successfully alleviated the clinical signs of HPPRRSV infection and reduced the mortality rate. Emergency vaccination was more efficient in controlling HPPRRSV, an acute form of the disease with epidemiologic characteristics that differed from typical PRRS.

The mechanism for emergency vaccination may be related to a quick adaptive immune response to restrict viral replication and proliferation, which could explain the immune protection conferred by the C strain of CSFV [13] and FMDV emergency vaccine [12]. Emergency vaccination might induce innate immunity. During rabies vaccination, the attenuated rabies virus spreads from the peripheral sites of inoculation to the CNS tissues, and triggers the substantial immune cell infiltration into the CNS. These cells had a major function in the early containment of rabies viral infections (i.e., cleaning rabies or preventing them from entering the CNS), particularly through the production of type I interferon [14]. If the attenuated rabies vaccines entered the CNS after the wild-type rabies virus, the vaccination would be ineffective $[14,15]$. Previous studies have provided very little explanation on the mechanism of PRRSV emergency vaccination. PRRSV variants possess 
different capacities for inducing or controlling innate immunity, which appears similar with rabies vaccination. Thus, we speculated that the attenuated PRRSV might trigger an innate immune response that subsequently controls HPPRRSV infection.

The significantly higher level of serum IFN- $\gamma$ in the vaccine-treated group at 10 DPI lasted until the end of the experiment (21 DPI). This process probably influenced the protection obtained by piglets from the vaccinated group. In a previous report [16], a swine serum IFN- $\gamma$ response was detected immediately after PRRSV infection and lasted for approximately 3 weeks. IFN- $\gamma$ is important for controlling PRRSV infection [17]. IFN- $\gamma$ could inhibit PRRSV replication more effectively than the type I interferon in vitro $[18,19]$. Furthermore, no neutralizing activities were detected in all of the serum samples (data not shown). This observation underlines the protective function of IFN- $\gamma$ during the early stages of PRRSV infection.

The viral load in tissues of infected pigs under the acute infection phase was one of indexes used to indicate PRRSV pathogenicity. The more virulent the strain is, the higher is the viral load in pigs [17]. In our study, the serum viral RNA load was significantly lower in the vaccinated group $(p<0.05)$ at 7 and 10 DPI. The severity of a clinical disease is highly associated with the viral load [20]. Thus, the lower serum viral RNA load might account for the minimal clinical signs and tissue lesions observed in the vaccinated group.

In this study, we developed an HPPRRSV contactinfection model by intramuscular infection. The infected pigs exhibited higher levels of viraemia at 3 DPI, thereby suggesting that the pigs transmitted the virus within 2 DPI, which may account for the rapid spread of the virus in herds [21]. PRRSV transmission is primarily via the respiratory route [22]. Our data indicated that the virus from the inoculation sites rapidly reached the lungs.

\section{Conclusions}

To the best of our knowledge, this is the first report that uses emergency vaccination to control HPPRRSV infection. The experiment demonstrated a reduction in viraemia by approximately $90 \%$ at 7 DPI to 10 DPI. The tissue lesions scores ranged from 10.6 to 6.4 and the mortality from $3 / 5$ to $0 / 5$ during the HPPRRSV contactinfection. These data may provide a useful reference for future methods of clinical HPPRRSV control.

\section{Competing interest}

The authors declared that they have no competing interests.

\section{Authors' contributions}

$X L$ and $L Q$ carried out the animal assays, the immunoassays and drafted the manuscript. ZY and RD conceived of the study, and participated in its design and coordination and helped to draft the manuscript. XW participated in the design of the study and performed the statistical analysis. All authors read and approved the final manuscript.

\section{Acknowledgement}

This work was funded by the Fundamental Research Funds for the Central Universities of China (QN2011106) and Start-up Funds for Northwest A\&F University PhD Research (2010BSJJ014).

\section{Author details}

${ }^{1}$ College of Animal Science and Technology, Northwest A\&F University, Yangling 712100, China. ${ }^{2}$ College of Veterinary Medicine, Northwest A\&F University, Yangling 712100, China.

Received: 20 October 2012 Accepted: 5 February 2013

Published: 9 February 2013

\section{References}

1. Tian K, Yu X, Zhao T, Feng Y, Cao Z, Wang C, Hu Y, Chen X, Hu D, Tian X. Emergence of fatal PRRSV variants: unparalleled outbreaks of atypical PRRS in China and molecular dissection of the unique hallmark. PLoS One 2007, 2(6):e526.

2. Feng $Y$, Zhao T, Nguyen T, Inui $K$, Ma $Y$, Nguyen $T H$, Nguyen VC, Liu D, Bui QA, To LT: Porcine respiratory and reproductive syndrome virus variants, Vietnam and China, 2007. Emerg Infect Dis 2008, 14(11):1774.

3. Tian ZJ, An TQ, Zhou YJ, Peng JM, Hu SP, Wei TC, Jiang YF, Xiao Y, Tong GZ: An attenuated live vaccine based on highly pathogenic porcine reproductive and respiratory syndrome virus (HP-PRRSV) protects piglets against HP-PRRS. Vet Microb 2009, 138(1):34-40.

4. Opriessnig T, Halbur P, Yoon KJ, Pogranichniy R, Harmon K, Evans R, Key K, Pallares F, Thomas P, Meng X: Comparison of molecular and biological characteristics of a modified live porcine reproductive and respiratory syndrome virus (PRRSV) vaccine (ingelvac PRRS MLV), the parent strain of the vaccine (ATCC VR2332), ATCC VR2385, and two recent field isolates of PRRSV. J Virol 2002, 76(23):11837-11844.

5. Cano JP, Dee SA, Murtaugh MP, Pijoan C: Impact of a modified-live porcine reproductive and respiratory syndrome virus vaccine intervention on a population of pigs infected with a heterologous isolate. Vaccine 2007, 25(22):4382-4391.

6. Zhou Z, Ni J, Cao Z, Han X, Xia Y, Zi Z, Ning K, Liu Q, Cai L, Qiu P: The epidemic status and genetic diversity of 14 highly pathogenic porcine reproductive and respiratory syndrome virus (HP-PRRSV) isolates from China in 2009. Vet Microb 2011, 150(3):257-269.

7. Cano JP, Dee SA, Murtaugh MP, Trincado CA, Pijoan CB: Effect of vaccination with a modified-live porcine reproductive and respiratory syndrome virus vaccine on dynamics of homologous viral infection in pigs. Am J Vet Res 2007, 68(5):565-571.

8. Wang $X$, Zhou Y, Li Y, Li Z, Jiang P: Pathogenicity of porcine reproductive and respiratory syndrome virus isolates with different NSP2 variation in Piglets. Chin J Anim Vet Sci 2011, 3:011.

9. Wang X, Li J, Jiang P, Li Y, Zeshan B, Cao J: GM-CSF fused with GP3 and GP5 of porcine reproductive and respiratory syndrome virus increased the immune responses and protective efficacy against virulent PRRSV challenge. Virus Res 2009, 143(1):24-32.

10. Halbur PG, Paul PS, Meng XJ, Lum MA, Andrews JJ, Rathje JA: Comparative pathogenicity of nine US porcine reproductive and respiratory syndrome virus (PRRSV) isolates in a five-week-old cesarean-derived, colostrumdeprived pig model. J Vet Diagn Invest 1996, 8(1):11.

11. Xiao XL, Wu H, Yu YG, Cheng BZ, Yang XQ, Chen G, Liu DM, Li XF: Rapid detection of a highly virulent Chinese-type isolate of porcine reproductive and respiratory syndrome virus by real-time reverse transcriptase PCR. J Virol Methods 2008, 149(1):49-55.

12. Golde WT, Pacheco JM, Duque H, Doel T, Penfold B, Ferman GS, Gregg DR Rodriguez LL: Vaccination against foot-and-mouth disease virus confers complete clinical protection in 7 days and partial protection in 4 days: use in emergency outbreak response. Vaccine 2005, 23(50):5775-5782.

13. Graham SP, Everett HE, Haines FJ, Johns HL, Sosan OA, Salguero FJ, Clifford DJ, Steinbach F, Drew TW, Crooke HR: Challenge of pigs with classical swine fever viruses after C-Strain vaccination reveals remarkably rapid protection and insights into early immunity. PLoS One 2012, 7(1):e29310.

14. Hooper DC, Roy A, Kean RB, Phares TW, Barkhouse DA: Therapeutic immune clearance of rabies virus from the CNS. Future Virol 2011, 6(3):387-397.

15. Hooper DC, Roy A, Barkhouse DA, Li J, Kean RB: Rabies virus clearance from the central nervous system. Adv Imag Elect Phys A 2011, 79:55-71. 
16. Wesley RD, Lager KM, Kehrli ME Jr: Infection with Porcine reproductive and respiratory syndrome virus stimulates an early gamma interferon response in the serum of pigs. Can J Vet Res 2006, 70(3):176.

17. Loving CL, Brockmeier SL, Vincent AL, Lager KM, Sacco RE: Differences in clinical disease and immune response of pigs challenged with a highdose versus low-dose inoculum of porcine reproductive and respiratory syndrome virus. Viral Immunol 2008, 21(3):315-326.

18. Gaudreault N, Rowland RRR, Wyatt C: Factors affecting the permissiveness of porcine alveolar macrophages for porcine reproductive and respiratory syndrome virus. Arch Virol 2009, 154(1):133-136.

19. Bautista $E$, Molitor T: IFN- $\gamma$ inhibits porcine reproductive and respiratory syndrome virus replication in macrophages. Arch Virol 1999, 144(6):1191-1200

20. Johnson W, Roof M, Vaughn E, Christopher-Hennings J, Johnson CR, Murtaugh MP: Pathogenic and humoral immune responses to porcine reproductive and respiratory syndrome virus (PRRSV) are related to viral load in acute infection. Vet Immunol Immunopathol 2004, 102(3):233-247.

21. Dwivedi V, Manickam C, Binjawadagi B, Linhares D, Murtaugh MP, Renukaradhya GJ: Evaluation of immune responses to porcine reproductive and respiratory syndrome virus in pigs during early stage of infection under farm conditions. Virol J 2012, 9:45.

22. Dee SA, Deen J, Cano JP, Batista L, Pijoan C: Further evaluation of alternative air-filtration systems for reducing the transmission of Porcine reproductive and respiratory syndrome virus by aerosol. Can I Vet Res 2006, 70(3):168.

doi:10.1186/1746-6148-9-26

Cite this article as: Li et al.: Emergency vaccination alleviates highly pathogenic porcine reproductive and respiratory syndrome virus infection after contact exposure. BMC Veterinary Research 2013 9:26.

\section{Submit your next manuscript to BioMed Central and take full advantage of:}

- Convenient online submission

- Thorough peer review

- No space constraints or color figure charges

- Immediate publication on acceptance

- Inclusion in PubMed, CAS, Scopus and Google Scholar

- Research which is freely available for redistribution 